\title{
A novel insulin formulation with a more rapid onset of action
}

\author{
S. Steiner • M. Hompesch • R. Pohl • P. Simms • \\ F. Flacke • T. Mohr • A. Pfützner • L. Heinemann
}

Received: 21 April 2008 / Accepted: 13 June 2008/Published online: 19 July 2008

(C) The Author(s) 2008

\begin{abstract}
Aims/hypothesis This study evaluates the pharmacodynamic and pharmacokinetic properties of the novel ultra-fast insulin product VIAject, a formulation of human soluble insulin and generally recognised as safe ingredients designed to increase the rate of absorption.

Methods We performed five euglycaemic glucose clamps (Biostator; target blood glucose $5 \mathrm{mmol} / \mathrm{l}$ ) in ten healthy volunteers. Using a crossover design with a fixed treatment order, $12 \mathrm{IU}$ human soluble insulin, $12 \mathrm{U}$ insulin lispro and 12 IU ultra-fast insulin were injected s.c. in the abdominal region on three study days. On the other two study days, 6 and 3 IU ultra-fast insulin were injected.

Results Subcutaneous injection of 12 IU ultra-fast insulin resulted in a time-action profile characterised by an even more rapid onset of action and maximal metabolic activity than insulin lispro: time to early half-maximal activity was $33 \pm 17 \mathrm{~min}(\operatorname{mean} \pm \mathrm{SD})$ vs insulin lispro $51 \pm 13 \mathrm{~min}$ vs human soluble insulin $66 \pm 15 \mathrm{~min}(p<0.05$ ultra-fast insulin $<$ insulin lispro $<$ human soluble insulin); time to
\end{abstract}

S. Steiner $\cdot$ R. Pohl $\cdot$ P. Simms $\cdot$ F. Flacke

Biodel,

Danbury, CT, USA

M. Hompesch

Profil Institute for Clinical Research,

San Diego, CA, USA

T. Mohr $\cdot$ A. Pfützner

IKFE,

Mainz, Germany

L. Heinemann $(\triangle)$

Profil Institut für Stoffwechselforschung,

D-41460 Neuss, Germany

e-mail: lutz.heinemann@profil-research.de maximal activity was $136 \pm 56$ min vs insulin lispro $152 \pm$ $30 \mathrm{~min}$ vs human soluble insulin $193 \pm 57 \mathrm{~min}(p<0.05$ ultra-fast insulin and insulin lispro $<$ human soluble insulin). The metabolic activity in the first $2 \mathrm{~h}$ after injection was higher with ultra-fast insulin and insulin lispro than with human soluble insulin (AUC glucose infusion rate [GIR] $0-120 \mathrm{~min}: 915 \pm 301$ and $781 \pm 174$ vs $580 \pm 164 \mathrm{mg} / \mathrm{kg}$; $p<0.05)$. A clear dose-response relationship was observed with the three doses of ultra-fast insulin: AUCGIR 0 $120 \min 12$ IU $915 \pm 301$ vs 6 IU $718 \pm 255$ vs 3 IU $524 \pm$ $262 \mathrm{mg} / \mathrm{kg}(p<0.05)$. The pharmacokinetic data confirmed the pharmacodynamic results.

Conclusions/interpretation This study shows that the onset of action of VIAject is faster than that of human soluble insulin and insulin lispro.

Keywords Insulin therapy · Prandial insulin .

Rapid-acting insulin analogues

$\begin{array}{ll}\begin{array}{l}\text { Abbreviations } \\ \text { AUCGIR }\end{array} & \text { AUC of glucose infusion rate } \\ \text { AUCINS } & \text { AUC of insulin concentration } \\ \mathrm{C}_{\max } & \begin{array}{l}\text { maximum insulin } \\ \text { concentration } \\ \text { glucose infusion rate }\end{array} \\ \mathrm{GIR} & \text { maximum GIR } \\ \mathrm{GIR}_{\max } & \text { time to } \mathrm{C}_{\max } \\ t \mathrm{C}_{\max } & \text { time to } \mathrm{GIR}_{\max } \\ t \mathrm{GIR}_{\max } & \end{array}$

\section{Introduction}

Rapid-acting insulin analogues were developed [1] to meet prandial insulin requirements more effectively. Rather than altering the primary structure of the insulin molecule, a new 
approach currently under clinical development pulls the zinc ions away from human insulin hexamers and simultaneously masks charges on the surface of the insulin molecule. This causes the insulin hexamers to dissociate and prevents re-association to the hexameric state upon s.c. injection. This is achieved by the addition of EDTA and citric acid. Using this approach, an ultra-fast insulin formulation for s.c. injection was developed (VIAject; Biodel, Danbury, CT, USA) [2]. The aim of this study was to determine the pharmacodynamic and pharmacokinetic properties of this insulin in comparison to the same dose of insulin lispro and human soluble insulin, and to study the dose-responsive properties of this novel insulin at two lower doses.

\section{Methods}

We recruited ten healthy volunteers (age 40 [19-61] years, mean [range]; BMI 22.5 [19.2-24.9] $\mathrm{kg} / \mathrm{m}^{2}$ ) to this openlabel study that used five euglycaemic glucose clamps (Biostator, mtb Medizintechnik, Ulm, Germany) with blood glucose value $5 \mathrm{mmol} / \mathrm{l}$ and basal i.v. insulin infusion $0.15 \mathrm{mU} \mathrm{kg}^{-1} \mathrm{~min}^{-1}$ administered at $2 \mathrm{~h}$ before until $8 \mathrm{~h}$ after glucose dose. The ethics committee of North Rhine in Germany approved this Good Clinical Practice study. Using a crossover study design with a fixed treatment order, 12 IU human soluble insulin (Humulin R; Eli Lilly, Indianapolis, IN, USA), 12 U insulin lispro (Humalog; Eli Lilly) and 12 IU of ultra-fast insulin (VIAject; Biodel) were injected s.c. into the abdominal wall on three study days. On two additional study days 6 and 3 IU of the ultra-fast insulin were studied. This insulin was a re-constituted, lyophilised regular human insulin. In this two-part formulation, the insulin and diluent can be shipped and stored without refrigeration. It is stable at room temperature and for at least two years when refrigerated and frozen. Re-constitution consists of withdrawing $10 \mathrm{ml}$ of diluents with a syringe and injecting it into the vial containing the lyophilised insulin. Reconstitution yields a single, liquid $10 \mathrm{ml}$ vial $(25 \mathrm{IU} / \mathrm{ml})$ and in liquid form it should be refrigerated.

Glucose infusion rates (GIR) as determined by the glucose clamp technique were the primary variable for analysis. Sixth-order polynomial functions were fitted to the individual baseline-corrected GIR profiles to determine the following pharmacodynamic summary measures: (1) maximum GIR $\left(\mathrm{GIR}_{\max }\right)$; (2) time to $\mathrm{GIR}_{\max }\left(t_{\mathrm{GIR}} \max \right) ;(3)$ time to early/ late half-maximal $\mathrm{GIR}_{\max }\left(t \mathrm{GIR}_{\max }+50 \%\right.$ and $t \mathrm{GIR}_{\max }-$ 50\%); and (4) AUCGIR for specified time intervals.

The secondary variable was the serum insulin concentration profile. From the insulin concentration over time data the following pharmacokinetic variables were derived: (1) maximum insulin concentration $\left(C_{\max }\right)$; (2) time to $C_{\max }$ $\left(t C_{\max }\right)$; (3) time to $50 \%$ of $C_{\max }\left(t C_{\max }+50 \%\right)$; (4) time to $50 \%$ of $C_{\max }$ after $C_{\max }\left(t C_{\max }-50 \%\right)$; and (5) the AUC of insulin concentrations (AUCINS) for specified time intervals. Human insulin serum concentrations (after administration of human soluble insulin and ultra-fast insulin) were measured by means of a commercial chemoluminescence assay (catalogue number 2-001; MLT-Research, Cardiff, $\mathrm{UK})$. The assay sensitivity was $0.25 \mu \mathrm{U} / \mathrm{ml}$. Insulin lispro serum concentrations were measured by means of a lisprospecific commercial RIA kit (catalogue number LPI-16K; Linco Research, St Charles, MO, USA). Analyses were performed by IKFE, Mainz, Germany. Pharmacokinetic variables were calculated directly from the assayed values. Since the assay employed for ultra-fast insulin and human soluble insulin measured endogenous insulin and the insulin administered at the glucose clamp procedure, the measured levels were adjusted for baseline and any values less than zero were set to zero. The respective pharmacokinetic variables were calculated from the adjusted data as follows: $C_{\max }$ and $t C_{\max }$ were reported from the observed adjusted maximum values, the early and late $t C_{\max } 50 \%$ were calculated by linear interpolation between the two closest time points, and the AUC values were calculated using the linear trapezoidal rule. As insulin lispro and ultrafast insulin/human soluble insulin were measured by different assays, no statistical analysis of concentration-dependent variables was made.

Differences in pharmacokinetic and pharmacodynamic variables were analysed (SAS version 8.02; SAS, Cary, NC, USA) using one-way ANOVA followed by a two-tailed Duncan's multiple range test if the ANOVA showed significance.

\section{Results}

Blood glucose levels during the glucose clamps were comparable on the different study days as were their swings. Specifically, blood glucose levels were: 12 IU ultra-fast insulin $5.0 \pm 0.2 \mathrm{mmol} / \mathrm{l}$ (coefficient of variation $4.7 \%) ; 12 \mathrm{U}$ insulin lispro $5.0 \pm 0.2 \mathrm{mmol} / \mathrm{l}(4.5 \%) ; 12 \mathrm{IU}$ human soluble insulin $4.9 \pm 0.4 \mathrm{mmol} / \mathrm{l}(7.7 \%) ; 6$ IU ultra-fast insulin $4.9 \pm 0.3 \mathrm{mmol} / \mathrm{l}(5.6 \%)$; and $3 \mathrm{IU}$ ultra-fast insulin $4.9 \pm 0.2 \mathrm{mmol} / \mathrm{l}(4.6 \%)$.

Pharmacokinetic variables obtained with 12 IU of ultrafast insulin, insulin lispro and human soluble insulin Figure 1a shows that subcutaneous injection of ultra-fast insulin resulted in a more rapid increase in serum insulin than did injection of insulin lispro, which, in turn was more rapid than human soluble insulin. While the difference between ultra-fast insulin and human soluble insulin was significant, the difference between ultra-fast insulin and 

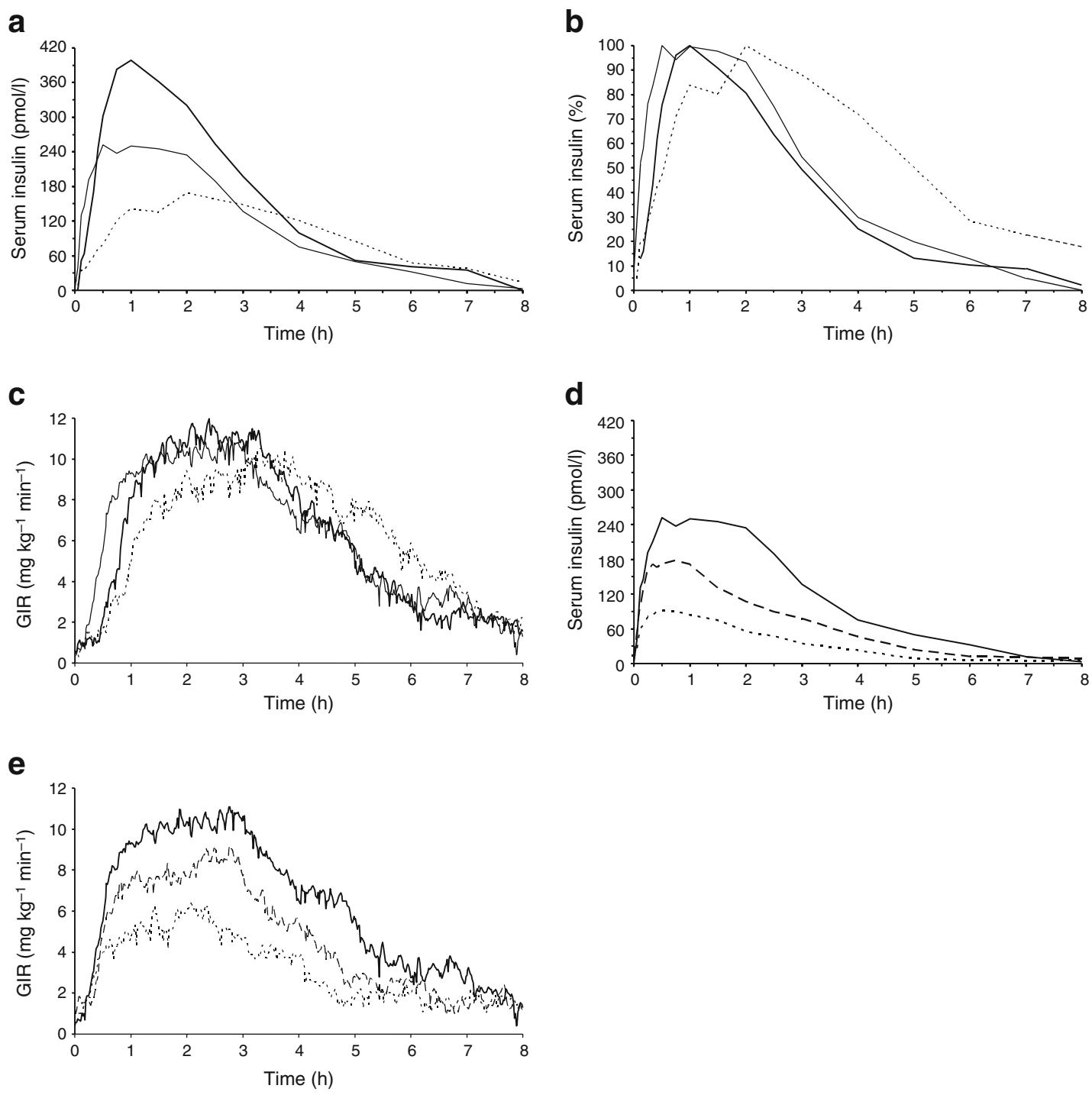

Fig. 1 Mean serum insulin profiles (a), normalised mean serum insulin levels (b) and GIR profiles (c) after baseline correction obtained after s.c. application of $12 \mathrm{IU}$ human soluble insulin (dotted lines), $12 \mathrm{U}$ insulin lispro (bold lines) and $12 \mathrm{IU}$ ultra-fast insulin (non-bold lines) in ten healthy participants. (b) For normalisation of the mean serum insulin levels the maximal serum insulin value

observed after s.c. injection with each of the three insulin formulations was set as $100 \%$ and all other values were calculated as a proportion of these. The dose-response relationship of the observed mean serum insulin levels (d) and GIRs (e) with two additional doses of ultra-fast insulin (6 IU, dashed lines; $3 \mathrm{IU}$, dotted lines) were also studied. To convert GIR in $\mathrm{mg} \mathrm{kg}^{-1} \mathrm{~min}^{-1}$ to $\mu \mathrm{mol} \mathrm{kg} \mathrm{km}^{-1} \mathrm{~min}^{-1}$ multiply by 5.5

insulin lispro failed to reach statistical significance $\left(t C_{\max }\right)$ (Table 1, Fig. 1a). The decline of serum insulin levels was also more rapid with the ultra-fast insulin and insulin lispro. Figure 1 also shows a normalised graph comparing the different pharmacokinetic timing profiles. Serum C-peptide levels showed a moderate decline from baseline levels after s.c. injection of the different insulin formulations in all cases, including the different doses of ultra-fast insulin (data not shown).

Pharmacodynamic variables obtained with 12 IU of ultrafast insulin, insulin lispro and human soluble insulin The

pharmacodynamic properties of the three different insulin formulations mirror the pharmacokinetic variables. Subcutaneous injection of 12 IU ultra-fast insulin resulted in a time-action profile characterised by a more rapid rise in glucose consumption $\left(t \mathrm{GIR}_{\max }+50 \%\right)$ in comparison to $12 \mathrm{U}$ insulin lispro and $12 \mathrm{IU}$ human soluble insulin (Table 1, Fig. 1b). Maximal metabolic activity $\left(t \mathrm{GIR}_{\max }\right)$ was observed earlier and the metabolic activity in the first $2 \mathrm{~h}$ after s.c. injection (AUCGIR 0-120) was higher with ultra-fast insulin than with human soluble insulin, but failed to reach statistical significance when compared with insulin lispro. Maximal and total metabolic activity 
Table 1 Pharmacokinetic and pharmacodynamic summary measures of 12 IU human soluble insulin, 12 U insulin lispro and 12, 6 and 3 IU ultrafast insulin

\begin{tabular}{|c|c|c|c|c|c|}
\hline Variable & $\begin{array}{l}\text { Human soluble insulin } \\
\text { (12 IU) }\end{array}$ & $\begin{array}{l}\text { Insulin lispro } \\
(12 \mathrm{U})\end{array}$ & $\begin{array}{l}\text { Ultra-fast insulin } \\
\text { (12 IU) }\end{array}$ & $\begin{array}{l}\text { Ultra-fast insulin } \\
\text { (6 IU) }\end{array}$ & $\begin{array}{l}\text { Ultra-fast insulin } \\
\text { (3 IU) }\end{array}$ \\
\hline \multicolumn{6}{|l|}{ Pharmacokinetic } \\
\hline$t C_{\max }+50 \%(\min )$ & $37 \pm 22$ & $26 \pm 10$ & $18 \pm 18$ & $7 \pm 3$ & $12 \pm 13$ \\
\hline$t C_{\max }(\min )$ & $120 \pm 70^{\mathrm{a}}$ & $66 \pm 34^{\mathrm{a}}$ & $60 \pm 43^{\mathrm{a}}$ & $51 \pm 48$ & $54 \pm 44$ \\
\hline$t C_{\max }-50 \%(\min )$ & $260 \pm 105^{\mathrm{a}}$ & $170 \pm 39^{\mathrm{a}}$ & $181 \pm 76^{\mathrm{a}}$ & $145 \pm 59$ & $126 \pm 44$ \\
\hline$C_{\max }(\mathrm{pmol} / \mathrm{l})$ & $209 \pm 51$ & $437 \pm 98$ & $325 \pm 142^{\mathrm{b}}$ & $204 \pm 71^{\mathrm{b}}$ & $111 \pm 33^{\mathrm{b}}$ \\
\hline AUCINS $0-120 \min ([\mathrm{nmol} / 1] \times \min )$ & $13.8 \pm 3.2$ & $36.2 \pm 7.9$ & $26.9 \pm 9.6^{\mathrm{b}}$ & $17.3 \pm 4.6^{\mathrm{b}}$ & $9.0 \pm 2.9^{\mathrm{b}}$ \\
\hline AUCINS $0-480 \min ([\mathrm{nmol} / 1] \times \min )$ & $46.3 \pm 15.2$ & $68.4 \pm 16.4$ & $52.9 \pm 14.8^{\mathrm{b}}$ & $30.8 \pm 8.4^{\mathrm{b}}$ & $16.1 \pm 6.5^{\mathrm{b}}$ \\
\hline \multicolumn{6}{|l|}{ Pharmacodynamic } \\
\hline$t \mathrm{GIR}_{\max }+50 \%(\min )$ & $66 \pm 15^{\mathrm{c}}$ & $51 \pm 13^{\mathrm{c}}$ & $33 \pm 17^{\mathrm{c}}$ & $35 \pm 17$ & $31 \pm 14$ \\
\hline$t \mathrm{GIR}_{\max }(\min )$ & $193 \pm 57^{\mathrm{d}}$ & $152 \pm 30^{\mathrm{d}}$ & $136 \pm 56^{\mathrm{d}}$ & $115 \pm 32$ & $111 \pm 41$ \\
\hline$t \mathrm{GIR}_{\max }-50 \%(\min )$ & $357 \pm 67$ & $295 \pm 54$ & $280 \pm 60$ & $270 \pm 72$ & $297 \pm 113$ \\
\hline $\operatorname{GIR}_{\max }\left(\mathrm{mg} \mathrm{kg}^{-1} \min ^{-1}\right)$ & $10.4 \pm 3.3$ & $11.9 \pm 2.5$ & $11.5 \pm 2.6^{\mathrm{e}}$ & $9.1 \pm 2.9^{\mathrm{e}}$ & $6.5 \pm 3.0^{\mathrm{e}}$ \\
\hline AUCGIR $0-120 \mathrm{~min}(\mathrm{mg} / \mathrm{kg})$ & $580 \pm 164^{\mathrm{f}}$ & $781 \pm 174^{\mathrm{f}}$ & $915 \pm 301^{\mathrm{fe}}$ & $718 \pm 255^{\mathrm{e}}$ & $524 \pm 262^{\mathrm{e}}$ \\
\hline AUCGIR $0-480 \mathrm{~min}(\mathrm{mg} / \mathrm{kg})$ & $2993 \pm 1045$ & $2977 \pm 753$ & $2991 \pm 709^{\mathrm{e}}$ & $2223 \pm 717^{\mathrm{e}}$ & $1597 \pm 848^{\mathrm{e}}$ \\
\hline
\end{tabular}

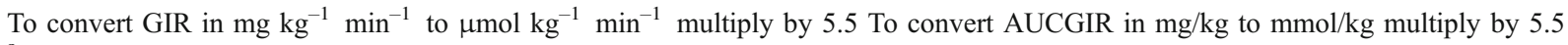

${ }^{a}$ Human soluble insulin $>$ insulin lispro, ultra-fast insulin

${ }^{\mathrm{b}} 12 \mathrm{IU}>6 \mathrm{IU}>3 \mathrm{IU}$

${ }^{\mathrm{c}}$ Human soluble insulin $>$ insulin lispro $>$ ultra-fast insulin

${ }^{\mathrm{d}}$ Human soluble insulin $>$ insulin lispro $>$ ultra-fast insulin

e 12 IU $>6$ IU $>3$ IU

${ }^{\mathrm{f}}$ Insulin lispro, ultra-fast insulin>human soluble insulin

$\left(\mathrm{GIR}_{\max }\right.$; AUCGIR) were comparable with all three insulin formulations.

Dose-response relationship The three dose levels of ultrafast insulin (3, 6 and $12 \mathrm{IU})$ showed the expected linear and proportional increases in insulin absorption (Table 1, Fig. 1c). In addition, the decline of late half-maximal levels tended to be more rapid with 6 and 3 IU than with $12 \mathrm{IU}$. With an increase in dose from 3 to 6 IU the AUCINS 0$120 \mathrm{~min}$ increased by a factor of 1.92 and from 6 to 12 IU by a factor of 1.56. The respective factors in the AUCGIR 0-120 min were 1.37 and 1.27 .

The time to early half-maximal action, time to maximal action and time to late half-maximal action after maximal action were comparable with all three ultra-fast insulin doses (Table 1, Fig. 1d). The maximal metabolic action and the AUCs were different with the three different doses.

Safety No serious adverse event occurred during this trial. Adverse events were headache and injection site pain, each reported by four participants $(27 \%)$.

\section{Discussion}

This study showed that the ultra-fast insulin, VIAject, is absorbed and exerts its action faster than either s.c. injected human soluble insulin or insulin lispro at the same dose. Further, the maximal and overall metabolic effects of all three insulin formulations were comparable at the same dose level, showing that when human insulin is mixed with ingredients that lead the insulin molecule to maintain the monomeric state and simultaneously mask charges on its surface, an improvement in insulin absorption and action is achieved. These observations in healthy participants warrant confirmation in patients with diabetes.

The pharmacodynamic response seen in the first hours after s.c. administration of this novel human insulin formulation came closer to that of physiological prandial insulin secretion than do rapid-acting insulin analogues such as lispro. The time to early half-maximal action is $15 \mathrm{~min}$ faster with insulin lispro than with human soluble insulin; however, ultra-fast insulin is $32 \mathrm{~min}$ faster than human soluble insulin and $17 \mathrm{~min}$ faster than insulin lispro. It remains to be established by direct measurements whether this led to a stronger suppression of hepatic gluconeogenesis, which helps to optimise postprandial metabolic control [3].

During the first $2 \mathrm{~h}$ after administration, half the dose of ultra-fast insulin produced a metabolic effect in the same range as that achieved with 12 IU human soluble insulin and insulin lispro over that period. Appropriately designed clinical trials are now needed to establish whether it is possible to meet prandial insulin require- 
ments as effectively with markedly reduced doses of ultrafast insulin (vs other insulins). Clearly, several clinically relevant questions such as intra-individual variability of the metabolic activity of ultra-fast insulin and the effectiveness in controlling postprandial glycaemia remain to be studied $[4,5]$.

In conclusion, this novel human insulin formulation appears to be a promising candidate for improving postprandial glycaemic excursions with a reduced risk of late postprandial hypoglycaemia.

Acknowledgement This study was supported by a research grant from Biodel.

Duality of interest S. Steiner is the inventor of VIAject and Chief Executive Officer of Biodel, Danbury, CT, USA. M. Hompesch is the Chief Executive Officer of Profil Institute for Clinical Research, San Diego, CA, USA. R. Pohl, P. Simms, F. Flacke and A. Pfützner are employees of Biodel and own shares/options. T. Mohr is an employee of IKFE, Mainz, Germany. L. Heinemann is a Chief Executive Officer of Profil, Neuss, Germany. M. Hompesch and L. Heinemann do not own shares/options in Biodel.
Open Access This article is distributed under the terms of the Creative Commons Attribution Noncommercial License which permits any noncommercial use, distribution, and reproduction in any medium, provided the original author(s) and source are credited.

\section{References}

1. Brange J, Owens DR, Kang S, Volund A (1990) Monomeric insulins and their experimental and clinical implications. Diabetes Care 13:923-954

2. Pohl R, Steiner S (2007) US Patent Number 7,279,457, 9 October 2007. Available from http://patft.uspto.gov/netacgi/nph-Parser? Sect $1=$ PTO1 $\&$ Sect $2=$ HITOFF $\& d=$ PALL $\& \mathrm{p}=1 \& u=\% 2$ Fnetahtml $\%$ 2 FPTO $\% 2$ Fsrchnum.htm \& $\mathrm{r}=1 \& \mathrm{f}=\mathrm{G} \& \mathrm{l}=50 \& \mathrm{~s} 1=7279457 . \mathrm{PN}$. $\& \mathrm{OS}=\mathrm{PN} / 7279457 \& \mathrm{RS}=\mathrm{PN} / 7279457$, accessed 18 June 2008

3. Bruttomesso D, Pianta A, Mari A et al (1999) Restoration of early rise in plasma insulin levels improves the glucose tolerance of type 2 diabetic patients. Diabetes 48:99-105

4. Heise T, Nosek L, Stender A et al (2004) Lower within-subject variability of insulin detemir in comparison to NPH insulin and insulin glargine in people with type 1 diabetes. Diabetes 53:1614-1620

5. Heinemann L, Heise T, Wahl LC et al (1996) Prandial glycaemia after a carbohydrate-rich meal in type I diabetic patients using the rapid acting insulin analogue [Lys(B28), Pro(B29)] human insulin. Diabet Med 13:625-629 